\title{
Retroviral-mediated IL-12 gene therapy for advanced murine tumors
}

\author{
Seon Hee Kim, ${ }^{1,2}$ Chung Sun An, ${ }^{2}$ \\ Hideaki Tahara, ${ }^{3,4}$ Chaehwa Park, ${ }^{5}$ \\ Michael T. Lotze, ${ }^{3,4}$ Paul D. Robbins ${ }^{4}$ and \\ Sunyoung $\mathrm{Kim}^{1,6}$
}

\author{
1 Institute for Molecular Biology and Genetics, Seoul National \\ University, Seoul 151-742, Korea \\ 2 Department of Biology, Seoul National University, Seoul 151-742, \\ Korea \\ 3 Department of Surgery, University of Pittsburgh School of Medicine, \\ Pittsburgh, PA 15261, U.S.A. \\ 4 Department of Molecular Genetics and Biochemistry, University of \\ Pittsburgh School of Medicine Pittsburgh, PA 15261, U.S.A. \\ 5 Division of Hematology/Oncology, Samsung Medical Center, \\ Seoul 135-230, Korea \\ 6 Corresponding author
}

Accepted 6 February 1997

Abbreviation: IL-12, interleukin 12

\begin{abstract}
Interleukin 12 (IL-12), a heterodimeric cytokine, promotes an effective antitumor response against tumors of various histological types when delivered systemically as a protein or locally by gene transfer. We investigated parameters that influenced the effectiveness of IL-12 retroviral-mediated gene therapy of cancer in animals using the murine breast cancer line TS/A. Syngeneic fibroblasts (TIB80), stably transduced with a retrovirus expressing murine IL-12, were used for peritumoral injection. Injection of fibroblasts into established tumors resulted in complete regression of tumor in $\mathbf{4 0} \%$ of animals in a dose dependent manner when treated on day 4 , and $20 \%$ when treated on day 8. Significant inhibition of growth of day 21 and day 40 tumors was observed following peritumoral injection of IL-12-expressing fibroblasts in a dosedependent manner. Delivery of IL-12 by syngeneic fibroblasts at a tumor site is effective in eradicating established, weakly immunogenic TS/A tumors.
\end{abstract}

Keywords : interleukin-12, cancer, gene therapy

\section{Introduction}

Gene therapy strategies recently have been widely applied to the treatment of cancer. One strategy involves immunotherapy where immunomodulatory proteins are delivered using either a viral or non-viral vector. For example, delivery of cytokine genes such as interleukin (IL-2) (Fearon et al., 1990; Gansbacher et al, 1990a), IL4 (Tepper et al., 1989), IL-12 (Tahara et al., 1994), TNF$\alpha$ (Asher et al., 1991), $\gamma$-INF (Gansbacher et al., 1990b), and GM-CSF (Dranoff et al., 1991) have all been shown to stimulate an immune response to mouse tumors. Alternatively, expression of specific co-stimulatory molecules such as CD80 (Freedman et al., 1991) or antigenic proteins such as HLA -B7.1(Crowley et al., 1990; Nabel et al., 1992) have been used to induce effective anti-tumor immune responses. An alternative strategy involves the use of suicide genes which converts an inactive prodrug to a cytotoxic drug (Moolten et al., 1991; Plautz et al., 1991), resulting in death of that cell and, to variable extent, the surrounding cells. It is also possible to deliver defective tumor suppressor genes such as p53 or Rb to tumor cells, which can suppress cell growth or induce apoptosis (Weinberg 1991; Zhang et al., 1993). An alternative, indirect approach for gene therapy of cancer is to deliver genes expressing proteins such as the multidrug resistance gene (MDR) to drug-sensitive cells, such as bone marrow stem cells, to facilitate protection during dose-escalated anti-tumor chemotherapy (Galski et al., 1989; Podda et al., 1992).

Of these approaches, cytokine-mediated cancer gene therapy is the most attractive in many aspects. First, the gene does not have to be delivered into the all tumor cells, as cytokine expression in a few target cells theoretically would be sufficient to elicit anti-tumor immune function. In addition, the effect of enhanced cytokine expression could induce systemic immune response, thereby treating metastatic tumors. Furthermore, although systemic administration of cytokines has been effective in a subset of patients, the associated systemic toxicity makes clinical application difficult (Tracy et al., 1988). The use of local gene transfer of specific cytokines reduces the toxicity associated with systemic administration, but enhances the therapeutic efficacy (Fearon et al., 1990; Gansbacher et al., 1990; Tahara et al., 1994). Furthermore, gene delivery can allow substantial levels of gene expression for a prolonged period, so gene transfer is ideal for delivery of unstable cytokines.

We investigated the anti-tumor effect of IL-12 in the context of retroviral gene therapy. IL-12 is a heterodimer consisting of p35 and p40 subunits (Kobayashi et al., 1990; Stern et al., 1990). IL-12 is produced mainly by professional antigen presenting cells such as activated macrophages, dendritic cells, and B cells (Gulber et al., 1991; Wolf et al., 1991). IL-12 functions mainly on NK and T-cells, stimulating production of IFN $-\gamma$ and other 
cytokines, enhancing the lytic activity of NK cells and promoting expansion of activated NK and T cells (Chan et al., 1991; Gately et al., 199; Nastala et al., 1994). L12 induces primarily a $T_{H} 1$ response promoting the development of an effective cell-mediated immunity (Manetti et al., 1993; Hsieh et al., 1993).

Delivery of recombinant IL-12 protein has a potent antitumor effect when administered by direct peritumoral injection or systemic administration (Brunda et al., 1993; Tahara et al.,1994). However, clinical administration of $\mathrm{IL}-12$ has been associated with several side effects (Atkins et al., 1996), suggesting that alternative strategies to deliver IL-12 may be required. Potent anti-tumor effects in established murine tumor models have been observed with IL-12, when delivered using either tumor cells or fibroblasts genetically engineered to secret murine IL-12 (Tahara et al., 1994; Tahara et al., 1995). In a series of experiments, it was shown that various tumor cells secreting IL-12 failed to establish tumors and that local peritumoral injection of IL-12 secreting allogeneic or syngeneic cells into established subcutaneous tumors resulted in regression and complete disappearance of these tumors in a dose-dependent manner. These results suggest that IL-12 gene therapy may be highly effective in treating human cancers.

We have further investigated factors affecting the antitumor potential of IL-12 in vivo using the murine breast cancer line TS/A. Here we report that perilesional injection of IL-12 expressing syngeneic fibroblasts exhibited potent anti-tumor effects. The therapeutic efficacy was influenced by the number of IL-12 expressing fibroblasts injected and the time of establishment of the tumor. Of particular significance, an effect on day 21 and day 40 tumors was also observed. These results, together with previously published reports (Tahara et al., 1994, 1995; Zitvogel et al., 1995), support the development of clinical trials using local delivery of IL-12.

\section{Materials and Methods}

\section{Tumor lines, animals, and in vivo tumor experiments}

The TS/A cell line is an aggressive and poorly immunogenic clone derived from murine breast adenocarcinoma (Nanni et al., 1983). This cell was maintained in the RPMl1640 containing 10\% fetal bovine serum, $100 \mathrm{U} / \mathrm{ml}$ penicillin and $200 \mu \mathrm{g} / \mathrm{ml}$ streptomycin. The syngeneic fibroblast line TIB80 from BALB/c (ATCC, TIB80) was maintained in DMEM containing $10 \%$ fetal bovine serum, penicillin and streptomycin as described above. The CRIP packaging line (Danos and Mulligan, 1988) and NIH3T3 cells were maintained in Dulbecco's modified Eagle's medium (DMEM) containing 10\% calf serum, 100 units of penicillin $/ \mathrm{ml}, 200 \mu \mathrm{g} / \mathrm{ml}$ streptomycin. The producer line derived from the CRIP packaging line was cultured under the same condition. The TS/A tumor cells and non-transformed fibroblast line TIB80 were transduced with recombinant retrovirus from CRIP-IL-12 and CRIPNEO producer lines as described above. Stably infected cells were selected in $0.75 \mathrm{mg} / \mathrm{ml} \mathrm{G} 418$ media and the G418-resistant colonies were pooled and used in murine experiments. To establish tumors in mice, TS/A cells were washed three times and resuspended at a density of 2 $\times 10^{5}$ cells $/ 100 \mu \mathrm{l}$, and inoculated subcutaneously in the shaved area of the left flank of BALB/c mice. Syngeneic BALB/c mice (Seoul National University) used in the experiments were all 4-week-old and female. Palpable tumors were detected consistently in 3-4 days postinoculation of tumor cells. To test antitumor effects of IL12 , cells harboring recombinant retroviruses or control cells were injected into the appropriate site, depending on the experiment. Five to ten mice per group were used in all animal experiments.

\section{Retroviral constructs, producer lines, and IL- 12-expressing fibroblasts.}

The retroviral vector containing genes for both p35 and p40 (TFG-mIL12) was previously described ( Tahara et al., 1995). In the first day, $1 \times 10^{6}$ cells of CRIP packaging line were seeded onto $100-\mathrm{mm}$ dish, and next day, retroviral constructs (MFG-mIL12 and MFG-NEO plasmids) were transfected into CRIP cells using the calcium phosphate precipitation method (Chen and Okayama, 1987). After about 2 weeks, G418-resistant colonies were formed which were then expanded sequentially onto 96-, 24- and 6-well plates. IL-12 assay was performed during expansion. Only IL-12-producing cells were chosen for further experiment. The CRIPmIL12 and CRIP-NEO producers were cultivated at a density of $1 \times 10^{6}$ cells $/ 60-\mathrm{mm}$ dish in $5 \mathrm{ml}$ of fresh DMEmedia at $37^{\circ} \mathrm{C}$. The supernatant containing virus was harvested $36 \mathrm{~h}$ later and filtered with $0.45 \mu \mathrm{m}$ pore syringe filter and the unconcentrated viral stock were either used directly or stored at $-80^{\circ} \mathrm{C}$. One million of TIB80 or TS/A cells were incubated with $5 \mathrm{ml}$ of viral supernatant in the presence of $8 \mu \mathrm{g} / \mathrm{ml}$ polybrene for 24 $\mathrm{h}$ in a $37^{\circ} \mathrm{C} \mathrm{CO}_{2}$ incubator. The viral supernatant were then replaced with fresh medium containing $0.8 \mathrm{mg} / \mathrm{ml}$ of G418. IL-12 was measured by both the antibodycapture bioassay and ELISA using rat antibody specific to IL-12 p75 heterodimer (Tahara et al., 1994, 1995; Zitvogel et al., 1994, 1995).

\section{Results}

To test the anti-tumor effect of locally-delivered IL-12 in vivo, we employed the procedure described previously using genetically engineered fibroblasts for delivery of IL-12, as summarized in Figure 1. The unique feature of 


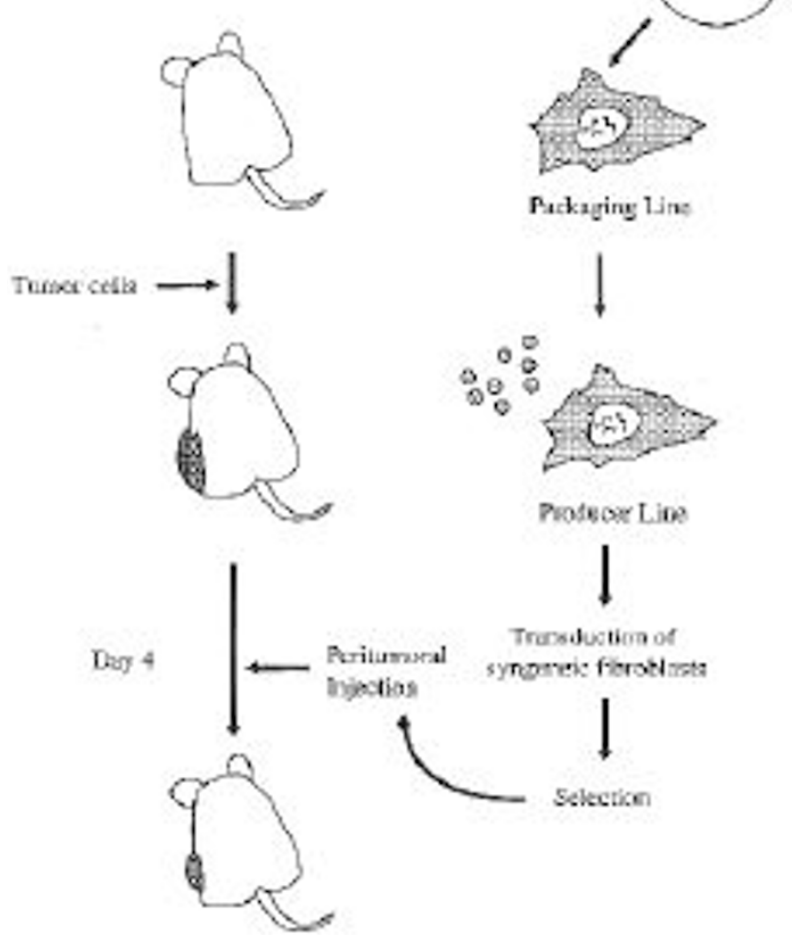

Figure 1. Overall procedure for retroviral-mediated IL-12 gene therapy of cancer. TFGIL-12 ( Tahara et al., 1995) was tranfected to the packaging line CRIP and the producer line constructed. Syngeneic fibroblasts (TIB80) were transduced with retroviral supernatant from the producer line and selected in the presence of G418. Antibioticresistant cell populations were subcutaneously injected to the appropriate site of mice.

this protocol is the use of normal syngeneic fibroblasts, not the tumor cells, to express and deliver IL-12. The retroviral vector expressing the two subunits of IL-12 and a neo ${ }^{r}$ marker gene was transfected into the packaging line CRIP to generate a stable producer line. Cell-free viral supernatant from the CRIP-IL12 producer was used to transduce the syngeneic fibroblast line TIB80 and both non-selected and G418-selected populations tested for the production of biologically active IL-12. G418-selected fibroblasts produced approximately $10 \mathrm{ng} / 10^{6}$ cells $/ 48 \mathrm{~h}$ of biologically active $\mathrm{IL}-12$ as measured in a 4 -day PHA blast assay performed on protein captured by solid phase antimurine p40 monoclonal antibody. The activity was confirmed to be murine IL-12 by ELISA using rat antibody specifically detecting IL-12 p75 heterodimer.

\section{Eradication of established tumor (day 4) by syngeneic fibroblasts expressing IL-12}

We initially evaluated the effect of peritumoral injection of syngeneic fibroblasts expressing IL-12 on the growth

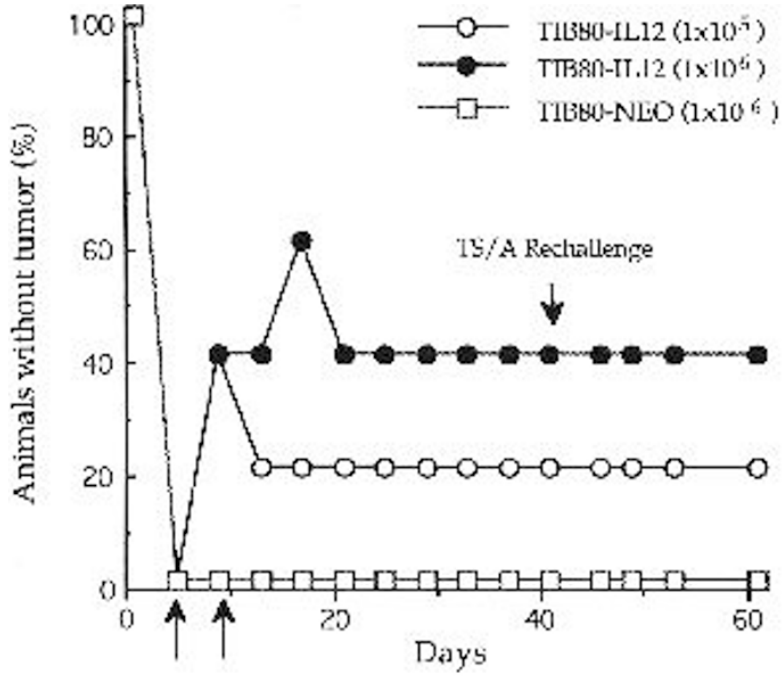

Figure 2. Eradication of established tumor with IL-12 gene therapy. Two $\times 10^{5} \mathrm{TS} / \mathrm{A}$ tumor cells were inoculated i.d. in the shaved area of the left flank of Balb/c mice. All mice had palpable tumors by day 4 . On days 4 and 8 , high $\left(1 \times 10^{6}\right)$ and low $\left(1 \times 10^{5}\right)$ concentrations of IL-12-expressing fibroblasts (TIB80-IL-12) or control cells (TIB80-NEO) were peritumorally injected as indicated as arrows on the X-axis. On day 40 , animals without tumor were rechallenged with $2 \times 10^{5}$ original TS/A tumor cells in the original tumor site. The tumor-free animals were counted every 4 days and compared to those of the TIB80-NEO-treated control group.

of established tumor at early stage, days 4 and 8 . The weakly immunogenic murine breast cancer line TS/A was subcutaneously injected into mice to induce tumor. At appropriate times, IL-12 expressing fibroblasts were injected into the tumor site or at distant sites as indicated, and tumor growth monitored. When mice were inoculated with $2 \times 10^{5}$ wild-type tumor cells TS/A on day 0 , palpable tumors (size $4 \mathrm{~mm}^{3}$ ) were readily detectable on day 4 and they gradually grew during the course of experiments. One million syngeneic fibroblasts expressing IL-12 (TIB80-IL12) were injected twice into the tumor site on days 4 and 8 . As a control, the same number of TIB80 cells transduced with the retrovirus lacking the IL-12 genes (TIB80-NEO) were used. All mice developed palpable tumors on day 4 . In control mice injected with TIB80-NEO, tumors continued to grow (Figure 2). In contrast, when mice were injected with TIB80-IL12, palpable tumors detected on day 4 disappeared in $40 \%$ of mice. Mice in which tumors were eradicated were rechallenged with $2 \times 10^{5}$ wild-type tumor cells on day 40. The injected mice were immune to rechallenge, suggesting the induction of long-term, systemic immunity conferred by IL-12. When $1 \times 10^{5}$ TIB80-IL12 cells were injected into the tumor site, the effectiveness of this therapy was reduced to $20 \%$ (Figure 2). Once the tumor was eradicated, however, the mice were immune to tumor rechallenge regardless of the number of IL-12expressing fibroblasts used in the first injection. These 


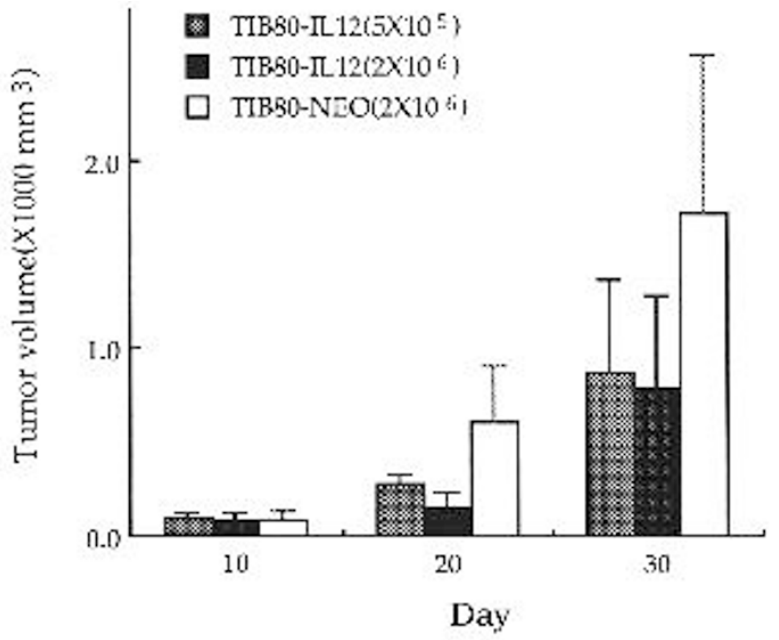

Figure 3. Delayed growth of established tumor with IL-12 gene therapy. Retroviralmediated IL-12 gene therapy was carried out as described in Figure 2. Tumor size was measured from mice in which tumor grew and compared between experimental groups. Tumor volume was calculated as (shorter diameter ${ }^{2} \times$ longer diameter; in $\mathrm{mm}^{3}$ ). Tumor-free animals were excluded from this analysis.

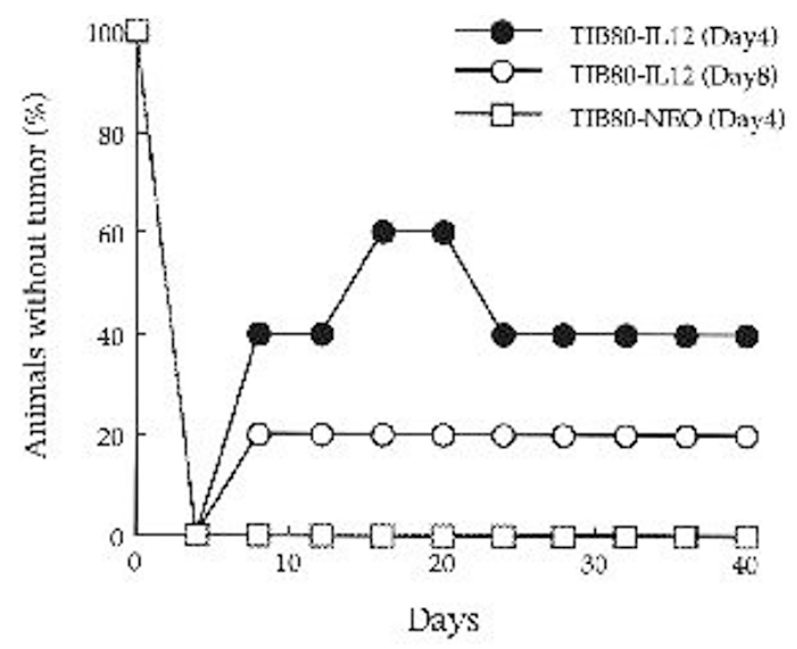

Figure 4. Effects of tumor ages on anti-tumor activity of IL-12. Retroviral-mediated IL-12 gene therapy was carried out as described in Figure 2 except that 1 X 106 TIB80-IL-12 cells were subcutaneously inoculated on days 4 and 8 , respectively. Control cells (TIB80-NEO) were injected only on day 4.

results indicate that peritumoral injection of syngeneic fibroblasts expressing IL-12 could eradicate early stage tumors and that this protocol could protect against rechallenge of wild type tumors. In mice where tumor growth was not eradicated, tumor growth was slowed by injection with cells expressing IL-12. In two separate experiments, tumor size in mice injected with TIB80IL12 was smaller by $30-50 \%$ at day 30 than in control mice, indicating that IL-12 was able to partially inhibit
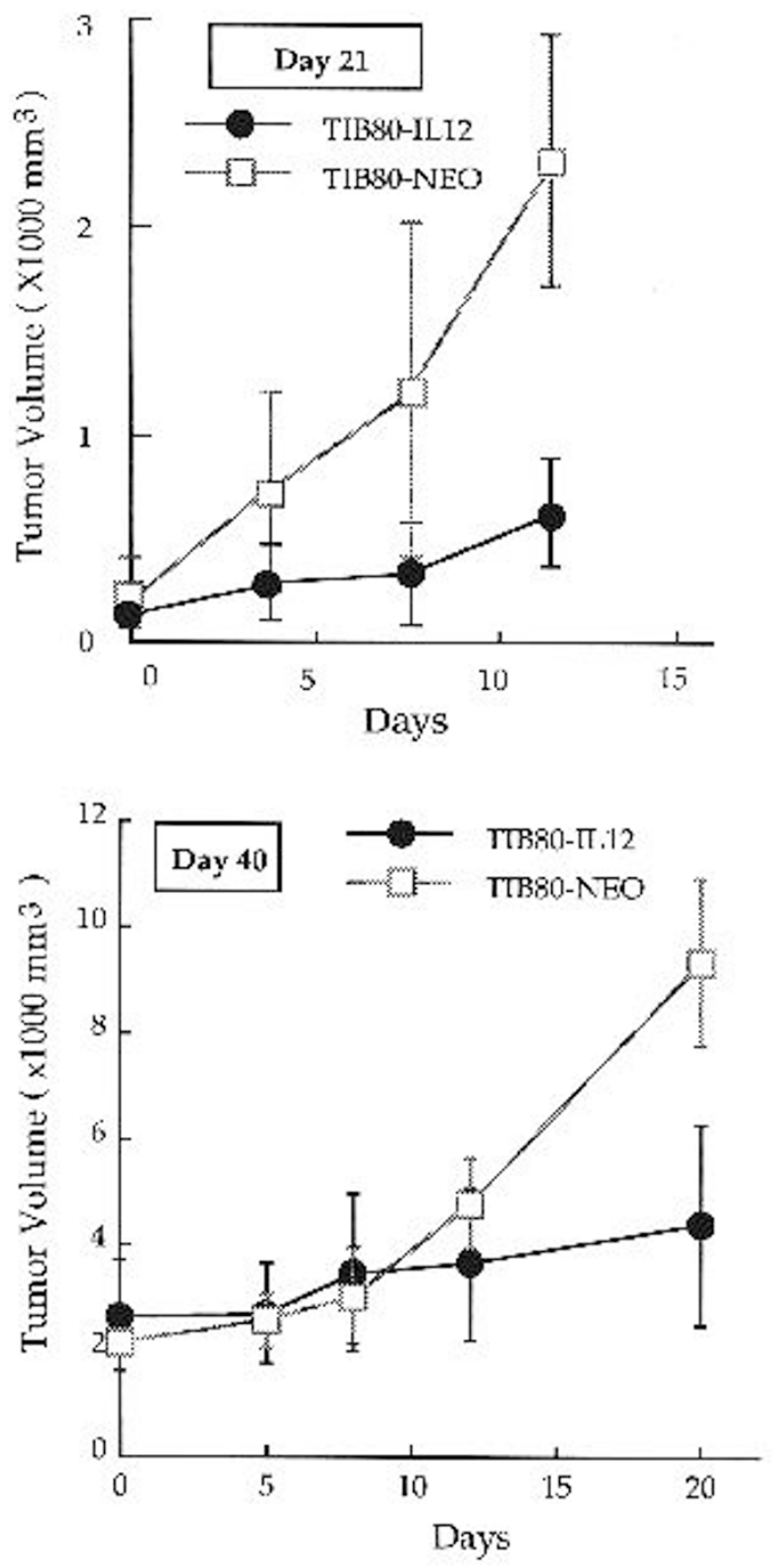

Figure 5. Effect of IL-12 gene therapy on advanced tumor. Tumors were induced as described in Materials and Methods. On day 21 and day $40,1 \times 10^{6}$ or $1 \times 10^{7}$ syngeneic fibroblast expressing with IL-12 (TIB80-IL-12) or control cells (TIB80-NEO) were peritumorally injected.

tumor growth even in mice with non-regressing tumor (Figure 3).

\section{Effects of tumor ages on anti-tumor activity of IL-12 expressing cells}

In the above experiments, early stage tumors were used to test the anti-tumor effects of IL-12. To test the effect of the age of tumor of the therapeutic efficacy of IL-12, we compared effects of peritumoral injection of TIB80- 
IL12 cells on day 4 and 8 tumors. In all control animals injected with TIB80-NEO cells, tumors developed and continued to grow. When $2 \times 10^{6}$ TIB80-IL12 cells were injected into the 4-day-old tumor, tumors were eradicated in $40-60 \%$ of animals (Figure 4 ) whereas in tumors injected on day 8 , tumor eradication occurred in $20 \%$ of animals. This result indicated that the age and/or size of tumor is important for effective treatment of tumors with IL-12 gene therapy.

We also tested whether IL-12 gene transfer could be used to slow down the growth of advanced tumors. TIB80-IL12 cells were injected into the tumor site of day 21 tumor. When mice were injected with $1 \times 10^{6}$ cells expressing IL-12 into the tumor site, the size of the tumor was reduced by almost 4-fold than in control mice (Figure $5 \mathrm{~A})$. It appeared that the more advanced tumor required a larger number of IL-12 expressing cells. Injection of 1 $\times 10^{6}$ cells expressing IL-12 into the tumor site of day 40 tumors did not seem to have significant effects on the growth of mature tumors (data not shown). However, when mice were injected with a higher dose of TIB80IL12 cells $\left(1 \times 10^{7}\right)$, the size of the tumors was reduced by more than 2 -fold than in control mice. It should be noted that injection of $1 \times 10^{7}$ cells resulted in tumor cell necrosis accompanying bleeding from the center of tumor mass into which IL-12-expressing cells were injected. However, this phenomenon was restricted to the tumor site. This result suggested that cells exp-ressing IL-12 could be effective against mature tumors, but the dose of transduced cells used for injection had to be determined carefully.

\section{Discussion}

Using a retrovirus-mediated gene therapy protocol, we have demonstrated that IL-12 has potent antitumor activity against murine tumors. Therapeutic intervention by IL-12 gene therapy could be initiated when tumors were well established. When the treatment was initiated on day 4 , established tumors were eradicated in $40 \%$ of animals. Even in mice which developed tumors, tumor growth was delayed especially during the late stage of tumor development. Tumor free mice were immune to a subsequent challenge with wild type indicator tumor, induction of systemic immunity.

The time of treatment was important as a smaller fraction of experimental mice were protected when tumors were treated on day 8 . We have previously shown that tumor regression in a day 7 model was as efficient as in a day 3 model (Zitvogel et al.,1995). One possibility for this difference is the level of IL-12 produced between transduced cells used in the two reports as our TIB80IL12 secreted lower amounts of IL-12. The second possibility is that there is a difference in the tumor model used, MCA 207 fibrosarcoma compared to the TS/A tumor in this report. For example it is known that TS/A is less immunogenic than MCA207.

To more closely simulate the clinical situation, we have tested anti-tumor effect on day 21 and day 40 tumors. At the concentration used for young tumors, our protocol significantly slowed growth of day 21 tumor. However the same numbers of IL-12 expressing cells did not have effects on growth of day 40 tumor. Only when the larger number of IL-12-expressing cells were used, tumor growth was significantly inhibited, despite hemorrhage around the injection site. This suggests that there might be a direct correlation between tumor age and therapeutic levels of IL-12, and that IL-12 might be effective against highly advanced tumor when the appropriate cell number is used. In overall, our results indicate that IL-12 gene therapy is a viable form of cancer treatment, and warrants further investigation.

\section{Acknowledgement}

This work was supported in part by research grants from the Korea Ministry of Science and Technology (SK) and the Ministry of Education (SK).

\section{References}

Asher, A. L., Mule, J. J., Kasid, A., Restifo, N. P., Salo, J. C., Reichert, C. M., Jaffe,G., Fendly, B., Kriegler, M. and Rosenberg, S. A. (1991) Murine tumor models transduced with the gene for TNF- $\alpha$. J. Immunol. 146: 3227-3234

Atkins M. B., Robertson, M., Gordon, M. S., Lotze, M. T., DuBois, J., Ritz, J., Sondler A., Edington, H. D. and Sherman, M. L. (1996) Phase I evaluation of intravenous recombinant human interleukin-12 (RHIL-12) in patient with advanced malignancies. Proc. ASCO 1996 15: 270

Brunda, M. J., Leopoldo, L., Warrier, R. R., Wright, R. B., Hubbard, B. R., Murphy, M., Wolf, S. F. and Gately, M. K. (1993) Antitumor and antimetastatic activity of IL-12 against murine tumor. J. Exp. Med. 178: 1223-1230

Chan, S. H., Kobayashi, D., Santoli, D., Perussia, B. and Trinchieri, G., (1992) Mechanism of IFN- $\gamma$-induction by NKSF. Role of transcription and mRNA stability in the synergistic interaction between NKSF and IL-2. J. Immunol. 148: 92

Chen, L. and Okayama, H. (1987) High efficiency transformation of mammalian cells by plasmid DNA. Mol. Cell. Biol. 7: 2745-2752

Crowley, N. J., Slingluff, C. L., Darrow, T. L. and Siegler, H. F. (1990) Generation of autologous melanoma-specific cytotoxic T-cells using HLA-A2-matched allogenic melanomas. Cancer Res. 50: 492-498

Danos, O. and Mulligan, R. C. (1988) Safe and efficient generation of recombinant retroviruses with amphotropic and ecotropic host range. Proc. Natl. Acad. Sci. USA 85 6460-6464

Dranoff, G., Jaffe, E. M., Lazenby, A., Golumbeck, P., Levitsky, H., Brose, K., Jackson, V., Hamada, H., Pardol, D. M. and Mulligan, R. C. (1993) Vaccination with irradiated tumor cells engineered to secrete murine GM-CSF stimulates potent, specific and long lasting antitumor immunity. Proc. Natl. Acad. Sci. USA 90: 3539-3543

Fearon, E. R., Pardol, D. M., Itaya, T., Golumbeck, P., Levitsky, H., Simons, J. W. Karasuyama, H., Vogelstein, B. and Frost, P. (1990) Interleukin-2 production by tumor cells bypasses $T$ help function in the generation of an antitumor response. Cell 60: 397- 
403

Freedman, A. S., Freeman, G. J., Rhynhart, K. and Nadler, L. M. (1991) Selective induction of B7/BB1 on interferon- $\gamma$ stimulated monocytes: a potential mechanism for amplification of T cell activation through the CD28 pathway. Cell. Immunol. 137: 429437

Galski, H., Sullivan, M., Willingham, M. C., Chin, K. V., Gottesman, M. M. and Pastan, I. (1989) Expression of a human multidrug resistance cDNA (MDR1) in the bone marrow of transgenic mice: Resistance to daunomycin-induced leukopenia. Mol. Cell. Biol. 9: 4357-4363

Gansbacher, B., Bannerji, R., Daniels, B., Zier, K. and Gilboa, E. (1990a) Retroviral vector mediated IFN- $\gamma$ gene transfer into tumor cells generates potent and long lasting antitumor immunity. Cancer Res. 50: 7820-7825

Gansbacher, B., Zier, K., Daniels, B., Cronin, K., Bannerji, R. and Gilboa, E. (1990b) Interleukin-2 gene transfer into tumor cells abrogates tumorigenicity and induces protective immunity. J. Exp. Med. 172: 1217-1224

Gately, M. K., Desai, B. B., Wolitsky, A. G., Quinn, P. M., Dwyer, C. M., Podlaski, F. J., Familetti, P. C., Sinigaglia, F., Chizzonnite, R. and Gulber, U. (1991) Regulation of human lymphocyte proliferation by a heterodimeric cytokine, IL-12. J. Immunol. 147: 874

Gulber, U., Chua, A. O., Schoenhaut, D. S., Dwyer, C. M. and Gately, M. K. (1991) Coexpression of two distinct genes is required to generate secreted bioactive cytotoxic lymphocyte maturation factor. Proc. Natl. Acad. Sci. USA 88: 4143-4147

Hsieh, C. S., Macatonia, S, E., Tripp, C. S., Wolf, S. F., O'garra, A. and Murphy, K. M. (1993) Development of Th1 CD4+ T cells through IL-12 production by Listeria-induced macrophages. Science 260: $547-549$

Kobayashi, M., Fitz, L., Ryan, M., Hewick, R. M., Clark, S. C., Chang, S., Loudon, R., Sherman, F., Perussia, B. and Trinchieri, G. (1989) Identification and purification of natural killer cell stimulatory factor (NKSF), a cytokine with multiple biologic effects on human lymphocytes. J. Exp. Med. 170: 827-845

Manetti, R., Parrondi, P., Giudizi, M. G., Piccini, M. P., Maggi, E., Trinchieri, G. and Romagnani, S. (1993) NKSF/LL12 induces T helper 1 specific immune responses and inhibits the development of IL4 producing Th cells. J. Exp. Med. 771: 1199-1204

Moolten, F. L., Wells, J. M., Heyman, R. A. and Evans, R. M. (1990) Lymphoma regression induced by ganciclovir in mice bearing a herpes thymidine kinase transgene. Hum. Gene Ther. 1: 125

Nabel, G. J., Chang, A., Nabel, E. G. and Plautz,G. (1992) Immunotherapy of malignancy by in vivo gene transfer into tumors. Hum. gene Ther. 3: 399

Nanni, P., DeGiovanni, C., Lollini, P. I., Nicoletti, G. and Prodi, G. (1983) TS/A: a new metastasizing cell line originated from a BALB/c spontaneous mammary adenocarcinoma. Clin. Exp. Metastasis 1: 373

Nastala, C. L., Edington, H. D., Storkus, W. J. and Lotze, M. T. (1993) Recombinant murine IL-12 mediates regression of both subcutaneous and metastatic murine tumors. Surg. Forum 44: 518-512

Plautz, G., Nabel, E. G. and Nabel, G. J. (1991) Selective elimination of recombinant genes in vivo with a suicide retroviral vector. New Biol. 7: 709

Podda, S., Ward, M., Himelstein, A., Richardson, C., Flor-Weiss, E., Smith, L., Gottesman, M. M., Pastan, I. and Bank, A. (1992) Transfer and expression of human multiple drug resistance gene into live mice. Proc. Natl. Acad. Sci. USA 89: 9676-9680

Stern, A. S., Podlaski, F. J., Hulmes, J. D., Pan Y. C. E., Quinn, P. M., Wolizky, A. G., Familleti, P. C., Stremlo, D. L., Truitt, T., Chizzonite, R. and Gately, M. K. (1990) Purification to homogeneity and partial characterization of cytotoxic lymphocyte maturation factor from human B-lymphoblastoid cells. Proc Natl Acad Sci USA 87: $6808-6812$

Tahara, H., Zeh III, H. J., Storkus, W. J., Pappo, I., Watkins, S., Gubler, U., Wolf, S., Robbins, P. D. and Lotze, M.D. (1994) Fibroblast genetically engineered to secrete IL12 can suppress tumor growth and induce antitumor immunity to a murine melanoma in vivo. Cancer Res. 54: 1-9

Tahara, H., Zitvogel, L., Storkus, W. J., Zeh III H. J., McKinney, T. G., Schreiber, R. D. Gubler, U., Gately, M. K., Robbins, P. D. and Lotze, M. T. (1995) Effective eradication of established murine tumors with IL-12 gene therapy using a polycistronic retroviral vector. J. Immunol. 154: 6466-6474

Tepper, R. I., Pattengale, P. K. and Leder, P. (1989) Murine IL-4 displays poten antitumor activity in vivo. Cell 57: 503-512

Tracy, K. J., Wei, H., Manogue KR et al. (1988) Cachectin/tumor necrosis factor induces cachexia, anemia and inflammation. J. Exp. Med. 167: 1211

Weinberg, R. A. (1901). Tumor suppressor genes. Science 254: 1138

Wolf, S. F., Temple, P. A., Kobayash, M., Trinchieri, G. and Perussia, B. (1991) Cloning of CDNA for NKSF, a heterodimeric cytokine with multiple biologic effects on T and NK cells. J. Immunol. 146: 3074-3081

Zhang, Y., Mukhopadhyay, T., Donehower, L. A., Georges, R. N. and Poth, J. A. (1993) Retroviral vector-mediated transduction of K-ras antisense RNA into human lung cancer cells inhibits expression of the malignant phenotype. Hum. Gene Ther. 4: 451

Zitvogel. L., Tahara, H., Cai, Q., Stockus, W. J., Muller, G., Wolf, S. F., Gately, M., Robbins, P. D. and Lotze, M. T. (1994) Construction and characterization of retroviral vectors expressing biologically active human interleukin-12. Hum. Gene Ther. 5: 14931506

Zitvogel, L., Tahara, H., Robbins, P. D., Stiorkus, W. J., Clarke, M. R., Nalesni, M. A and Lotze, M. T. (1995) Cancer immunotherapy of established tumors with IL-12 Effective delivery by genetically engineered fibroblasts. J. Immunol. 155: 1393-1403 